\title{
Multi-axial Fatigue of Head-Hardened Pearlitic and Austenitic Manganese Railway Steels: A Comparative Study
}

Dhar, S.; Ahlström, J.; Zhang, X.; Danielsen, H. K.; Juul Jensen, D.

Published in:

Metallurgical and Materials Transactions A: Physical Metallurgy and Materials Science

Link to article, DOI:

10.1007/s11661-020-05941-8

Publication date:

2020

Document Version

Peer reviewed version

Link back to DTU Orbit

Citation (APA):

Dhar, S., Ahlström, J., Zhang, X., Danielsen, H. K., \& Juul Jensen, D. (2020). Multi-axial Fatigue of Head-

Hardened Pearlitic and Austenitic Manganese Railway Steels: A Comparative Study. Metallurgical and Materials Transactions A: Physical Metallurgy and Materials Science, 51, 5639-5652. https://doi.org/10.1007/s11661-02005941-8

\section{General rights}

Copyright and moral rights for the publications made accessible in the public portal are retained by the authors and/or other copyright owners and it is a condition of accessing publications that users recognise and abide by the legal requirements associated with these rights.

- Users may download and print one copy of any publication from the public portal for the purpose of private study or research.

- You may not further distribute the material or use it for any profit-making activity or commercial gain

- You may freely distribute the URL identifying the publication in the public portal 

railway steels: A comparative study

\author{
S. Dhar ${ }^{1 *}$, J. Ahlström², X. Zhang ${ }^{3}$, H.K. Danielsen ${ }^{1,}$ and D. Juul Jensen ${ }^{3}$ \\ ${ }^{1}$ Department of Wind Energy, Technical University of Denmark, Roskilde, DK-4000, Denmark \\ ${ }^{2}$ Department of Industrial and Materials Science, Chalmers University of Technology, Gothenburg, SE-41296, Sweden \\ ${ }^{3}$ Department of Mechanical Engineering, Technical University of Denmark, Kgs. Lyngby, DK-2800, Denmark \\ * Corresponding Author; E-mail: somrita.dhar@gmail.com
}

Abstract:

Switches and Crossings (S\&Cs) in rail networks suffer from damage and deformation due to severe loading and complex geometric shape. This paper presents a comparative study of the cyclic deformation characteristics and fatigue behavior of two typical crossing materials namely head hardened pearlitic steel and Hadfield manganese steel, as well as the associated microstructural changes. Both uniaxial and biaxial loading (proportional and non-proportional) are studied. The pearlitic steel endured higher number of cycles to failure for a given strain amplitude compared to the manganese steel. The cyclic response of manganese steel was significant hardening whereas softening was observed for the pearlitic steel except under biaxial non-proportional loading. The microstructures developed in the two types of steels after deformation are characterized by optical (OM) and transmission electron microscopy (TEM). TEM micrographs reveal that the deformed microstructure of the pearlitic steel consists of threading dislocations and dislocation tangles in the ferrite lamellae. The microstructures in the manganese steel after the different loadings are composed of dislocation cells with dislocation tangles inside, intersected by straight stacking fault lamellae. The observed microstructures are related to the results of the mechanical test and the suitability of the steels for use in S\&Cs is discussed.

\title{
Introduction:
}

Different parts of the rail network are subjected to different types of stress conditions, where rail wheel contact induces very high contact stresses due to rolling and sliding. S\&Cs, experiencing high contact and impact stresses, are more susceptible to damage and deformation due to their complex geometric shape as compared to other parts of the rail. This leads to more frequent failures and large maintenance cost of S\&Cs. The two most common types of steels used in railway crossings are head hardened pearlitic steels and austenitic manganese steel, also known as Hadfield steel. Pearlitic steels possess properties like good tensile strength, fracture toughness and wear resistance whereas Hadfield steel possesses excellent work hardening ability as well as good fracture toughness and wear resistance. The stresses encountered by the rail surface are transient, multiaxial, non-proportional and in different directions [1]. The cyclic loading induces large strains in the surface layers of the rail from where cracks initiate by Rolling Contact Fatigue (RCF) mechanisms. Rail wheel interaction induces cyclic elastic stresses in the entire rail, which can lead to High Cycle Fatigue (HCF), but at the surface layer, close to the rail/wheel contact, plastic deformation and ratcheting strains accumulate which are often evaluated using Low Cycle Fatigue (LCF) experiments [2]. Several studies have been conducted on cyclic plasticity over the last decades. It has been demonstrated that damage is dependent on many factors including the type of loading, the presence of stress raisers and residual stresses in the material [1]. Under the conditions of strain controlled loading, the material can exhibit cyclic hardening, cyclic softening or cyclic saturation. This is strongly related to the material microstructure including dislocation density and arrangement, as well as sub-structure formation [3].

For manganese steels, fatigue behavior is affected by both dislocation and twinning mechanisms. It has been generally accepted that the high strain hardening in manganese steel is due to deformation by slip as well as twinning [4-6]. The interaction of twins with dislocations provides additional hardening to the material. Another theory suggests a rearrangement of $\mathrm{C}$-atoms in the $\mathrm{C}-\mathrm{Mn}$ cluster in the core of the dislocations imparts additional hardening [7-8]. Fatigue studies by Kang et al. [9] suggested that the LCF process and failure of manganese steel at low strains are mainly controlled by dislocation dominated cyclic deformation structures. Fatigue properties of manganese steels have been 
Table 1: Typical chemical composition of the two different grades of steels examined in this study.

examined in some previous studies. Rittel et al. [10] studied the cyclic properties of coarse grained cast manganese steel and found a pronounced hardening effect. Studies by Schilke et al. [11] and Kang et al. [9] found initial cyclic hardening followed by cyclic softening until failure. Chen et al. [12] studied the effect of pre-hardening on the LCF behavior of manganese steel. Pronounced hardening followed by cyclic stability but no softening was observed, and pre-deformation induced twins in the structure which influenced fatigue life. The role of twinning or stacking faults and their interaction with dislocations in LCF is not well understood. Also, most of the previous studies were performed under uniaxial loading. It is expected that a change in the mode of loading, for example pure torsion or biaxial, will generate differences in structure as well as the mode of fracture and is more realistic for the condition at S\&Cs [13-14].

For pearlitic steels diverse softening-hardening behavior has been reported in the literature by different authors. Previous studies of uniaxial LCF on rail steels [15-17] have indicated initial softening for the first $10 \%$ of fatigue life followed by cyclic stabilization. Asitha et al. [18] showed that microstructural features like the pearlite inter-lamellar spacing have strong relation with the cyclic plasticity behavior of the material. Also, the ferrite cementite content can affect the cyclic behavior. Sunwoo et al. [19] studied the effect of interlamellar spacing on the cyclic deformation behavior and observed that cyclic softening occurs with fine interlamellar spacing, while both cyclic softening and hardening is prevalent depending on the strain amplitude, when the interlamellar spacing is coarse or intermediate. In recent years a few experimental studies on multiaxial fatigue of rail steels have been attempted [20-22]; however, the correlation between the mechanical properties and the microstructure under uniaxial or multiaxial fatigue is not clear.

The aim of this work is to perform a comparative study on the cyclic deformation characteristics and fatigue behavior of head hardened pearlitic and manganese steel. To the best of the authors' knowledge, it is the first time such a comparison has been made with respect to the low cycle fatigue behavior under conditions of uniaxial and biaxial loading including proportional and non-proportional loading. To investigate well-defined conditions, different laboratory scale low cycle fatigue experiments have been performed and the mechanical properties have been correlated with the microstructure developed in the steels. The work has led to novel understanding of how the material behavior of the surface layers of rails develops under RCF loading and the potentials of the two materials for RCF exposure in S\&Cs are discussed.

\section{Experimental Procedure:}

\section{Materials}

The two types of materials examined are head hardened pearlitic steel $(0.8 \mathrm{wt} . \% \mathrm{C})$ and austenitic manganese steel (13 wt.\% Mn). The typical chemical composition of the steels is given in Table 1.

\begin{tabular}{|c|c|c|c|c|c|c|c|c|c|c|}
\hline Material & Element & $\mathrm{C}$ & $\mathrm{Mn}$ & $\mathrm{Si}$ & $\mathrm{Cr}$ & $\mathrm{Cu}$ & $\mathrm{P}$ & $\mathrm{Ni}$ & $\mathrm{S}$ & $\mathrm{Fe}$ \\
\hline $\begin{array}{c}\text { Pearlitic } \\
\text { Steel, } \\
\text { R350HT }\end{array}$ & Wt.\% & 0.8 & 1.21 & 0.48 & 0.094 & 0.073 & 0.020 & 0.033 & 0.018 & 97 \\
\hline $\begin{array}{c}\text { Manganese } \\
\text { Steel }\end{array}$ & Wt.\% & 1.17 & 12.7 & 0.5 & 0.12 & 0.044 & 0.031 & 0.062 & $<0.001$ & 85 \\
\hline
\end{tabular}

Table 2: Mechanical Properties of the two different grades of steel used in this study.

\begin{tabular}{|l|l|l|l|l|l|}
\hline Material & Tensile Strength & Yield Strength & Young's Modulus & Elongation & Hardness \\
\hline $\begin{array}{l}\text { Pearlitic Steel, } \\
\text { R350HT }\end{array}$ & $\sim 1260 \mathrm{MPa}$ & $\sim 850 \mathrm{MPa}$ & $\sim 206 \mathrm{GPa}$ & & $\begin{array}{l}400 \\
\text { surface; } 330 \\
\text { HV at 20 mm } \\
\text { from surface. }\end{array}$ \\
\hline Manganese Steel & $\sim 750 \mathrm{MPa}$ & $\sim 365 \mathrm{MPa}$ & $\sim 203 \mathrm{GPa}$ & $20 \%$ & $\sim 220 \mathrm{HV}$ \\
\hline
\end{tabular}


The microstructure of the pearlitic steel consists of two phases: ferrite and cementite with an interlamellar spacing of 100 $\mathrm{nm}$ and average pearlite colony size of $10 \mu \mathrm{m}$, whereas the manganese steel has single phase austenitic grains with a very large average size in the order of $500 \mu \mathrm{m}$. Figure 1 shows the microstructures of the two steels. The average hardness of the manganese steel was $220 \mathrm{HV}$. The pearlitic steel was head hardened and thus had a gradient of hardness from $400 \mathrm{HV}$ near the surface decreasing gradually with increasing depth down to $330 \mathrm{HV}$ at $20 \mathrm{~mm}$ from the surface.

Samples for the experiments were cut out from crossings extracted from the Danish railway network. Hardness studies showed that the depth of deformation during service leading to work hardening was confined to first 2-3 $\mathrm{mm}$ for the pearlite and $10 \mathrm{~mm}$ for the manganese steel [23]. Samples for fatigue testing of the pearlitic rail grade were thus taken from the rail head around 3-4 millimeters beneath the running surface. Because of the head hardening, slight variations in hardness levels in the volumes from which the test bars are taken is expected (roughly $20 \mathrm{HV}$ ). For the manganese steel, the samples were obtained from a depth of $15 \mathrm{~mm}$ from the surface, as it is found that the volumes here will be free from any service-induced deformation [23]. This means that both types of samples are in the undeformed condition. Figure 1a corresponds to the microstructure of the pearlitic steel from the non-deformation zone at a depth of $4 \mathrm{~mm}$ from the rail head surface and Figure 1c Figure to the microstructure of the manganese steel from the undeformed zone at a depth of $15 \mathrm{~mm}$ from the rail running surface where the samples for mechanical testing were obtained respectively.
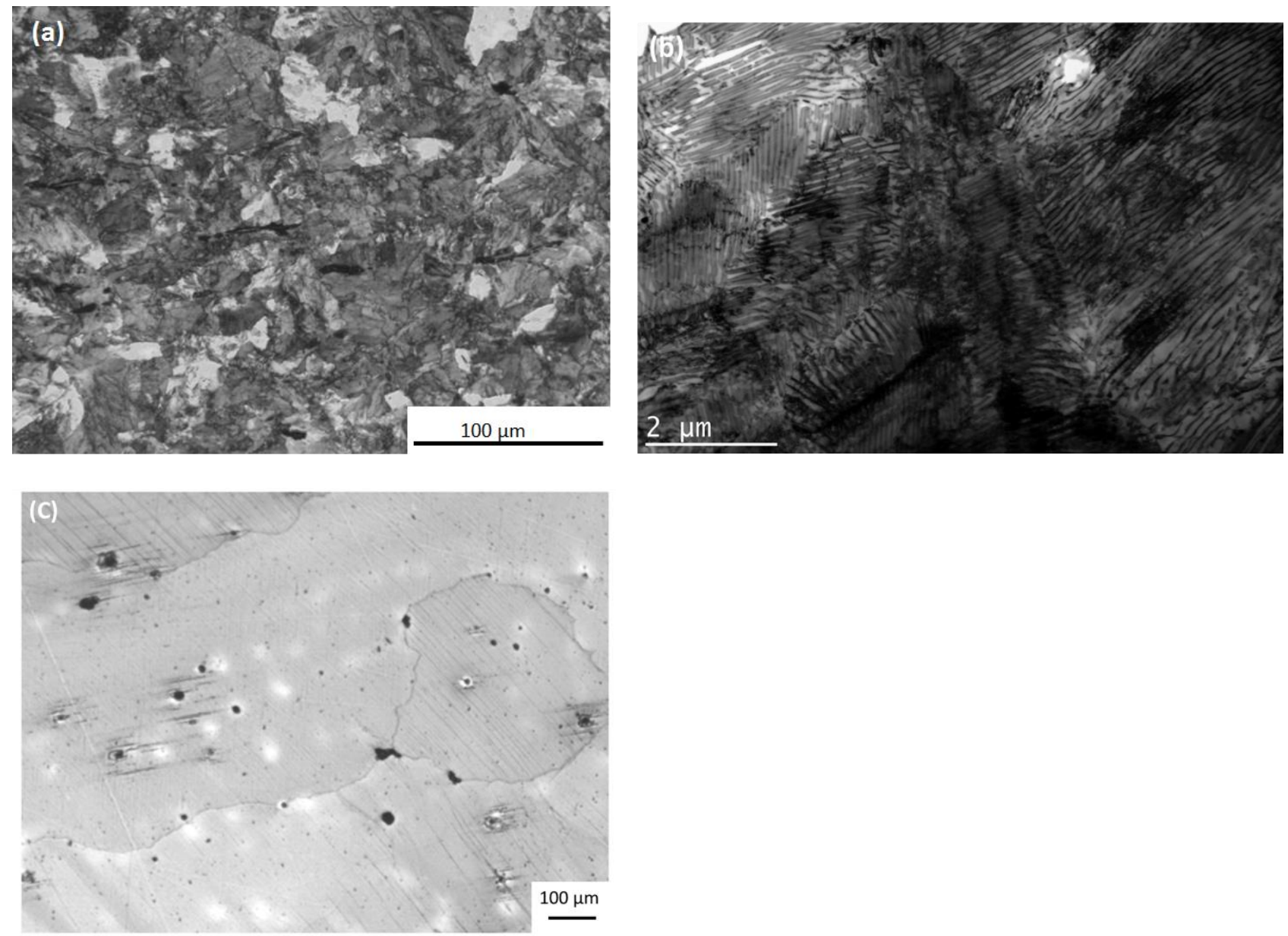

Figure 1: Micrographs of the two different steels used in the study (a) Optical micrograph \& (b) Transmission Electron micrograph of pearlite steel from $4 \mathrm{~mm}$ from the rail head surface and (c) optical micrograph of manganese steel from $15 \mathrm{~mm}$ from the rail running surface, i.e., both in the undeformed conditions. The black dots in figure $\mathrm{c}$, are inclusions present in the steel. The lines are artifacts from sample preparation. 
A schematic drawing of the fatigue test bars is given in Figure 2. The test bars are solid cylinders having a gauge diameter of $10 \mathrm{~mm}$ and a gauge length of $20 \mathrm{~mm}$. Outside the gauge length, a large radius $(100 \mathrm{~mm})$ was adopted to minimize the stress concentration without compromising buckling stability. The samples were extracted so that the axis of the test bars was parallel to the rolling direction. The test bars were ground and polished to mirror finish before testing. Low cycle strain controlled fatigue tests with constant strain amplitude were performed using a strain rate of $10^{-2} \mathrm{~s}^{-1}$ on an MTS 809 axial/torsion testing system, with a biaxial clip-on extensometer with a gauge length $12 \mathrm{~mm}$ that independently records axial strain and surface shear strain. Throughout testing, peak tensile and compressive stresses were recorded for each cycle. Throughout testing, peak tensile and compressive stresses were recorded for each cycle. In addition, complete strain-stress loops were obtained at defined intervals to acquire the hysteresis loop development. All tests were conducted at room temperature. The specimens and the procedures for uniaxial loading were done following ASTM guideline ASTM E606M- Standard Test Method for Strain-Controlled Fatigue Testing [24]. The conditions for the tests were:

1. Uniaxial (tension-compression) tests at a strain amplitude of $0.6 \%$.

2. Biaxial tests under tension-compression and torsion at strain amplitudes, which would give an equivalent strain amplitude of $0.6 \%$ at the gauge surface.

According to von Mises theory, the equivalent strain, axial strain, and shear strain can be related as

$$
\varepsilon_{e q}=\sqrt{\varepsilon^{2}+\frac{\Upsilon^{2}}{3}}
$$

where $\varepsilon_{e q}$ is the equivalent strain, $\varepsilon$ is the axial strain and $\Upsilon \Upsilon$ is the shear strain.

The different loading paths are shown in Figure 3. In case of uniaxial loading, there is no shear strain and the equivalent strain is the same as the axial strain. Two sets of uniaxial tests were done at the strain amplitude of $0.6 \%$ : strain controlled equal tension compression giving Strain Ratio $\left(\mathrm{R}_{\varepsilon}=\frac{\varepsilon_{\min }}{\varepsilon_{\max }}\right) R_{\varepsilon}=-1$ and strain controlled axial fatigue with a mean compressive strain of $0.9 \%$ giving $R_{\varepsilon}=5$. For biaxial loading both in-phase proportional ( $0^{\circ}$ phase difference) and outof-phase non-proportional loading $\left(90^{\circ}\right.$ phase difference) were conducted. For both these cases, the axial strain was selected to be $0.424 \%$ and the shear strain was $0.735 \%$ to obtain an equivalent of $0.6 \%$ nominal strain amplitude, even if the non-proportional loading case in each moment yields an equivalent strain below $0.6 \%$.

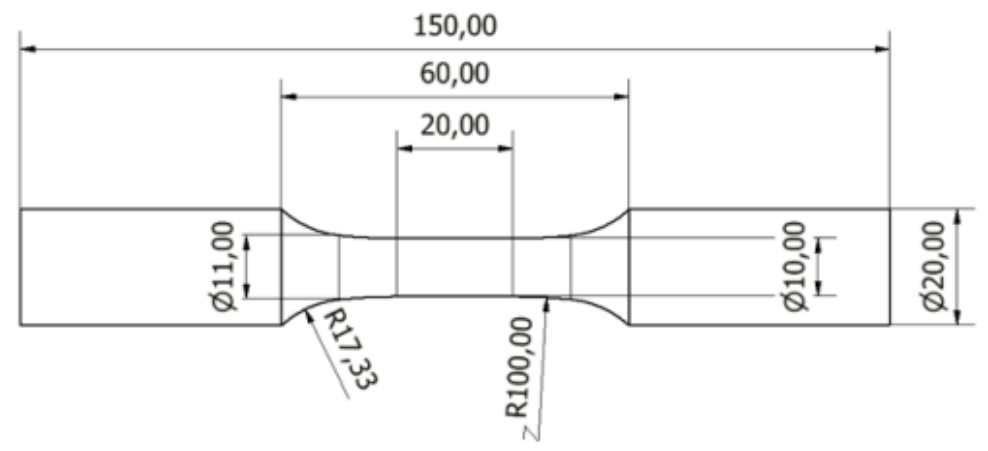

Figure 2: Schematic drawing of fatigue specimens (all dimensions in $\mathrm{mm}$ ). 
(a)

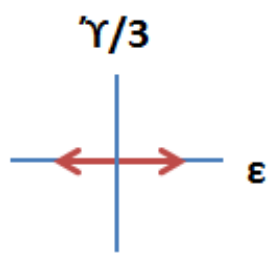

(b)

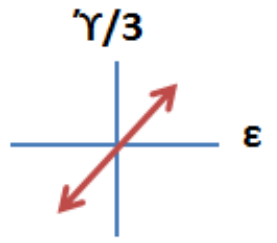

(c)

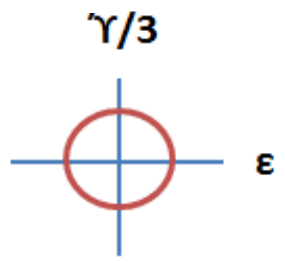

Figure 3: The loading paths for different conditions (a) linear strain path (uniaxial strains with no shear strain), (b) oblique strain path (axial with in-phase shear strains) and (c) circular path (axial with out-of-phase shear strains).

\section{Microstructure study}

The microstructures of the deformed specimens were studied using optical microscopy $(\mathrm{OM})$ for which the samples were ground, polished and finally etched with $4 \%$ Nital. The detailed features of the cyclic deformation microstructures under different loading conditions after the failure of the two different steels were analyzed using a Jeol 2000FX Transmission Electron Microscope (TEM) operating at 200kV. The specimens for TEM studies were obtained from the gauge part of the fatigue deformed specimens. The transverse surface was studied, and specimens were obtained as close to the surface of the specimen as possible to be at strain values near to $0.6 \%$. Thin TEM foils were prepared by electropolishing [25]. The dislocation density and also the stacking fault width were determined from the TEM images by the linear intercept method [26].

\section{Hardness Measurement}

The micro hardness measurements were conducted on the fatigued samples after the tests using a Vickers hardness measurement tester with a load of $0.5 \mathrm{~kg}$ and a dwell time of 20 seconds. The measurements were made across the radius from the surface to the centre of the cylindrical samples with a step size of $0.2 \mathrm{~mm}$. 

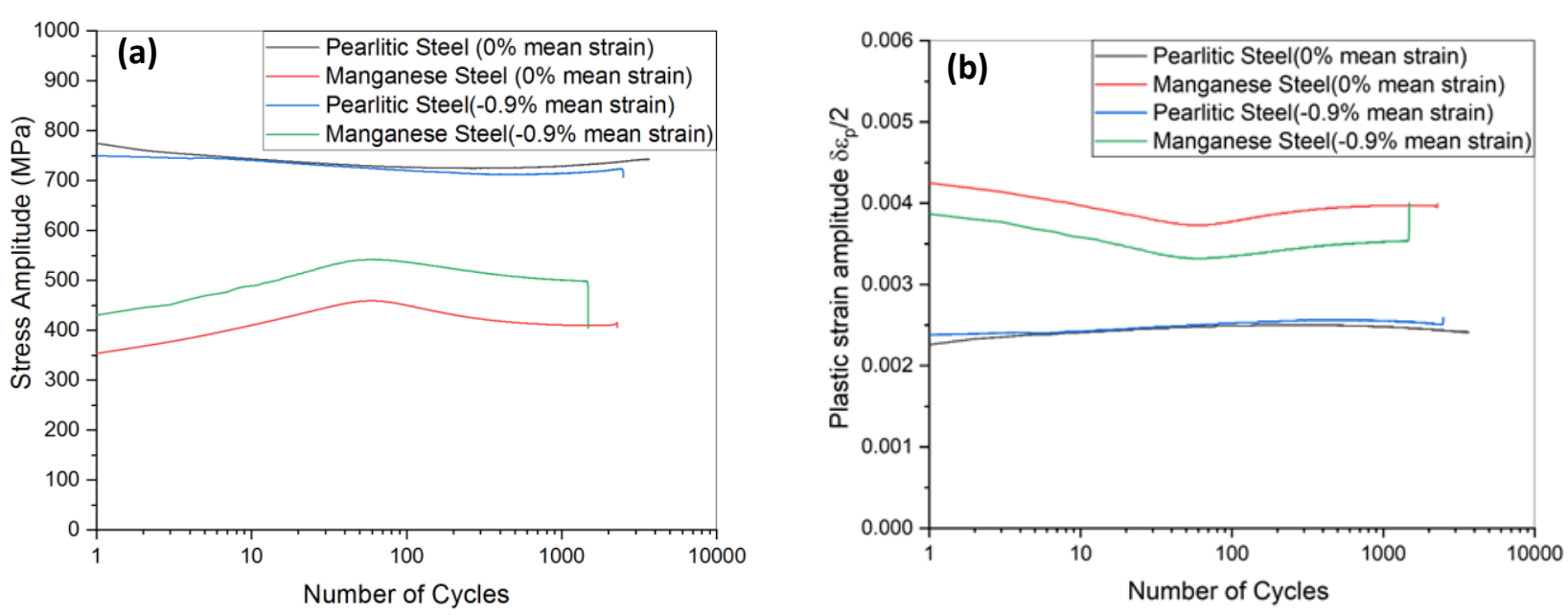

151 Figure 4: Uniaxial LCF (a) axial stress amplitude vs number of cycles and (b) plastic strain amplitude vs number of cycles.
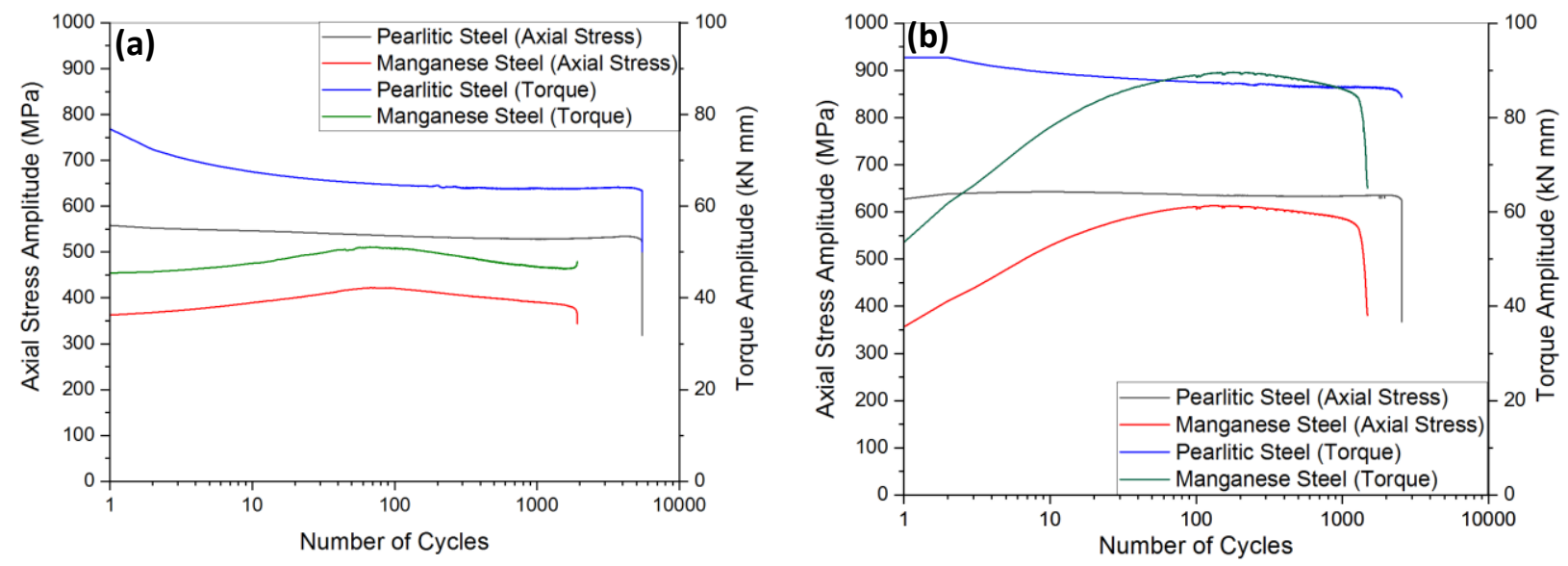

153 Figure 5: Biaxial LCF (axial + torsion) (a) in-phase proportional and (b) out-of-phase non-proportional loading showing 154 axial stress and torque amplitude vs number of cycles.

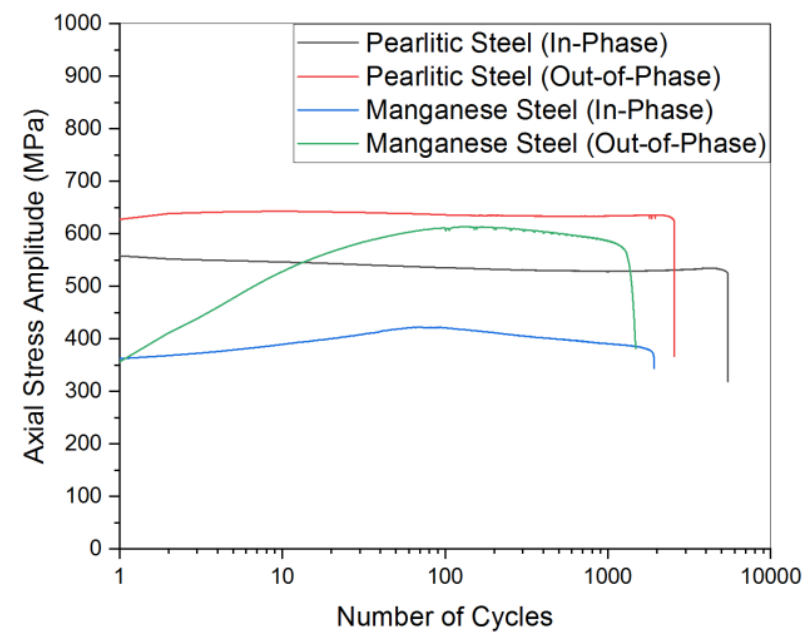

156 Figure 6: Comparison of uniaxial stress amplitude with number of cycles for both steels for biaxial loading. 
Table 3: The cycles to failure, CHR, and CSR of the different steels under different conditions of loading:

\begin{tabular}{|c|c|c|c|c|c|}
\hline $\begin{array}{l}\text { Loading } \\
\text { Condition }\end{array}$ & $\begin{array}{l}\text { Strain } \\
\text { amplitude }\end{array}$ & Material & $\mathbf{N}_{\mathrm{f}}$ & CHR & CSR \\
\hline \multirow[t]{4}{*}{ Uniaxial } & \multirow[t]{2}{*}{$0.6 \%$} & Pearlitic Steel & 3660 & 0 & 0.05 \\
\hline & & Manganese Steel & 2278 & 0.30 & 0.10 \\
\hline & \multirow{2}{*}{$\begin{array}{l}0.6 \% \quad(0.9 \% \\
\text { compressive } \\
\text { mean strain) }\end{array}$} & Pearlitic Steel & 2490 & 0 & 0.05 \\
\hline & & Manganese Steel & 1480 & 0.26 & 0.07 \\
\hline \multirow{2}{*}{$\begin{array}{l}\text { Biaxial } \\
\text { (proportional } \\
\text { loading) }\end{array}$} & \multirow{2}{*}{$\begin{array}{l}0.6 \% \\
\text { equivalent }\end{array}$} & Pearlitic Steel & 5471 & & \\
\hline & & Manganese Steel & 1924 & & \\
\hline \multirow{2}{*}{$\begin{array}{l}\text { Biaxial (non- } \\
\text { proportional } \\
\text { loading) }\end{array}$} & \multirow{2}{*}{$\begin{array}{l}\sim 0.6 \% \\
\text { equivalent }\end{array}$} & Pearlitic Steel & 2556 & & \\
\hline & & Manganese Steel & 1485 & & \\
\hline
\end{tabular}

159

For the manganese steel there is strong initial hardening followed by softening and then failure. Hardening was observed only for the initial few percents of the fatigue life, whereas softening prevailed for most of the fatigue life. No saturation stage was observed. In strain controlled fatigue testing, the plastic strain amplitude is a major governing factor. The plastic strain amplitude decreased initially due to hardening in all cases. The manganese steel under uniaxial loading had a very high hardening ratio of nearly 0.3 compared to the softening ratio of 0.1 . Under similar conditions of strains, at $0.6 \%$ strain amplitude, the highest life is obtained for uniaxial loading and the lowest for non-proportional loading. Failure criteria is decided as when the load drops to $20 \%$ of the peak load.

For pearlitic steel in uniaxial and biaxial in-phase proportional loading, there are three stages present. First, there is a decrease in stress amplitude due to softening, followed by cyclic saturation and a slight increase in stress amplitude due to hardening until fracture. For biaxial non-proportional loading, there is an initial hardening within the first two cycles followed by softening, cyclic saturation and failure. The fatigue life is highest for the biaxial in-phase proportional loading followed by uniaxial loading and the lowest life is seen for biaxial non-proportional loading. It should be noted that this is valid in strain or displacement controlled load situations; if the loading is better characterized with a stress amplitude, the increased hardening caused by non-proportional loading will likely lead to lower plastic strains and thus less fatigue damage [27].

A direct comparison between uniaxial and biaxial low cycle fatigue cannot be made unless the equivalent stress values are obtained. However, use of solid specimens (as used in this work) instead of tubular specimen because of the machining challenges for the manganese steel, restricts direct calculation of equivalent stress values. The normal stress is uniformly distributed whereas the general shear stress is dependent on the radius, shear stress being maximum at the surface and zero at the center. Due to plasticity, and non-linear response on plastic straining, the shear stress in each location is not readily computed. However, the strain is always well defined, and the uniaxial stress can also be used as a comparison tool for biaxial loading whether proportional or non-proportional. In case of pearlitic steel, in-phase proportional biaxial loading shows softening behavior like uniaxial loading. The softening ratios for the two conditions are nearly identical. This is expected as biaxial proportional loading maintains a straight strain path at any radial position (does not cause any change in strain path) and just adds to the shear component. Out-of-phase non-proportional biaxial loading of pearlitic steel shows higher initial hardening due to the strain path change after a quarter cycle and activation of latent slip systems. Whereas the hardening ratio is zero for uniaxial and in-phase proportional loading, a hardening ratio of 0.024 is obtained for out-of-phase non-proportional loading based on axial stress calculations. For manganese steel, the in-phase proportional biaxial curve is similar to the uniaxial curve. Non-proportional loading gives a much increased hardening rate. The cyclic hardening ratio is found to be around 0.7 based on axial stress calculations. In non-proportional out-ofphase loading the maximum shear stress plane rotates with time in every cycle causing activation of multiple slip systems and their mutual interactions [28]. The lowest hardening is observed in case of biaxial in-phase proportional loading. For 
in-phase proportional and uniaxial loading in manganese steel the amplitude developed is lower than in pearlite but biaxial out-of-phase non-proportional loading generates high hardening causing stress levels in line with the pearlitic steel.

The effect of mean strain on the two materials has been studied. The pearlitic steel is insensitive to mean strain hardening whereas for manganese steel, there is an increase in stress amplitude for the cases with negative mean strain as compared to those without a mean strain for the same strain amplitudes. This shows that manganese steel is sensitive to hardening due to the mean strain. This additional hardening reduces the fatigue ductility and causes earlier occurrence of micro cracks and thereby reduces the fatigue life. This reasoning is valid in displacement or strain controlled loading situations. The presence of a mean strain did not seem to affect the life of pearlitic steel for similar strain amplitudes. For pearlitic steel, the strain hardening saturates within the initial cycle and thereafter softens until failure with the cyclic softening rates being identical to loading without a mean strain for same strain amplitudes.

A comparison between the pearlite and manganese steels reveals the maximum stress amplitudes and torque amplitudes reached at all the strain amplitudes are higher for the pearlitic grade. This correlates with the higher hardness of pearlitic grade steel. Also in all cases, the manganese steel has very high plastic strain amplitudes compared to pearlitic grade under similar conditions. This is due to the lower cyclic flow stress of the manganese steel. The fatigue life of the pearlitic steel is higher compared to the manganese steel under similar constant strain amplitude conditions. Higher hardness and strength leads to lower plastic strains in the material and thus an increase in fatigue life. It is generally observed that hardened materials demonstrate cyclic softening whereas softer material exhibit cyclic hardening in fatigue tests[29-30].

Figures 7-12 show the hysteresis loops for the two materials under different loading conditions. For the manganese steel under all conditions, there is a shift of the tip of the hysteresis loop upwards towards higher stress indicating cyclic hardening whereas the trend is reverse for pearlitic grade indicating cyclic softening for all cases except biaxial nonproportional loading. The shape of the loop is different for the two materials under similar conditions. For the pearlitic grade, the loops are generally narrower as compared to the manganese steel, which has a broadened loop due to lower cyclic flow stress. In uniaxial and biaxial proportional loading, the hysteresis loops show a sharp tip at the maximum and minimum strains; however, under biaxial out-of-phase non-proportional loading the tips of the hysteresis loop get rounded. In non-proportional loading, the maximum values of axial and shear strains do not occur simultaneously.
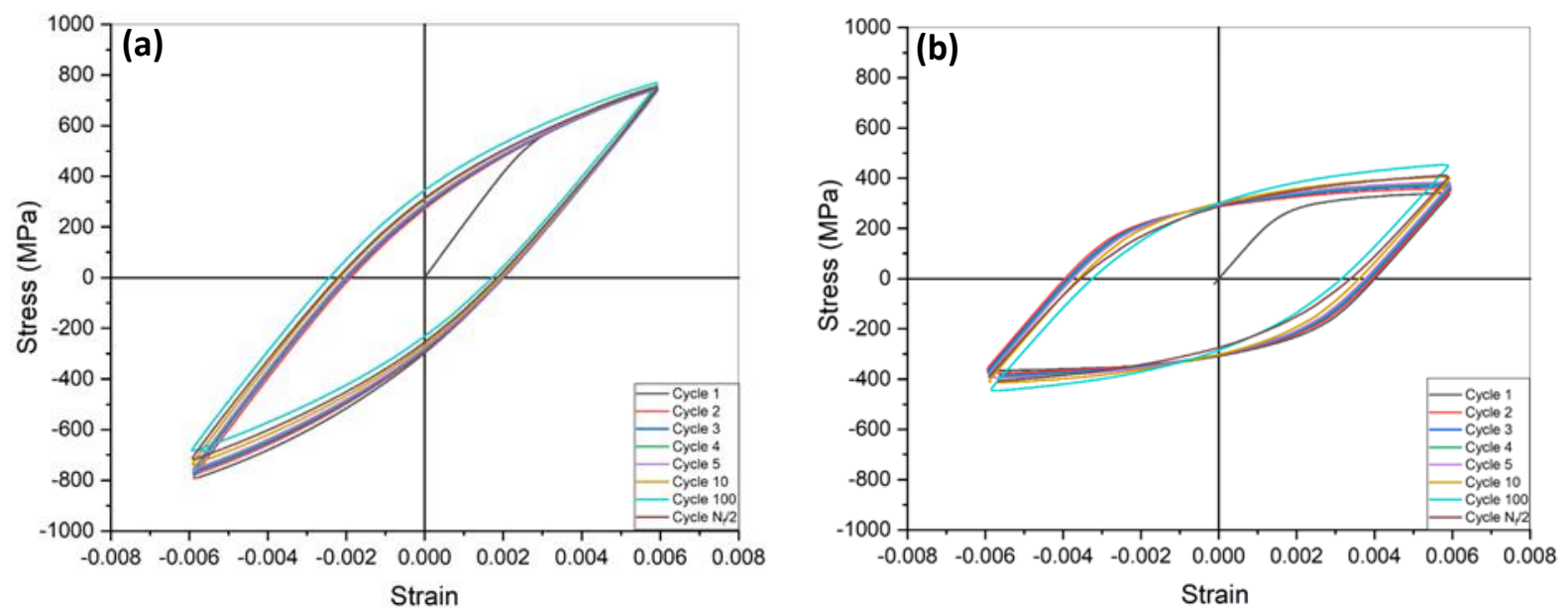

Figure 7: Hysteresis loops developed for $0.6 \%$ axial strain amplitude (a) pearlitic steel and (b) manganese steel. 

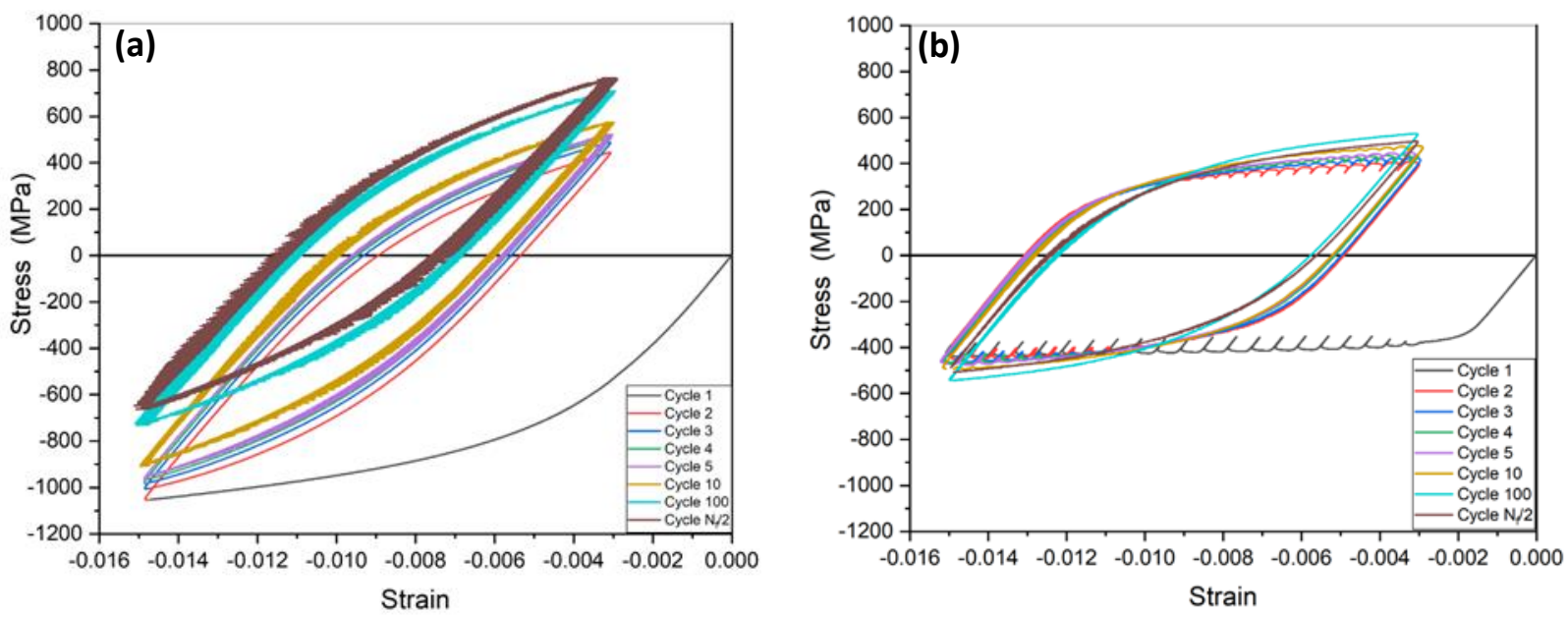

Figure 8: Hysteresis loops developed for $0.6 \%$ strain amplitude with $-0.9 \%$ mean strain (a) pearlitic steel and (b) manganese steel.
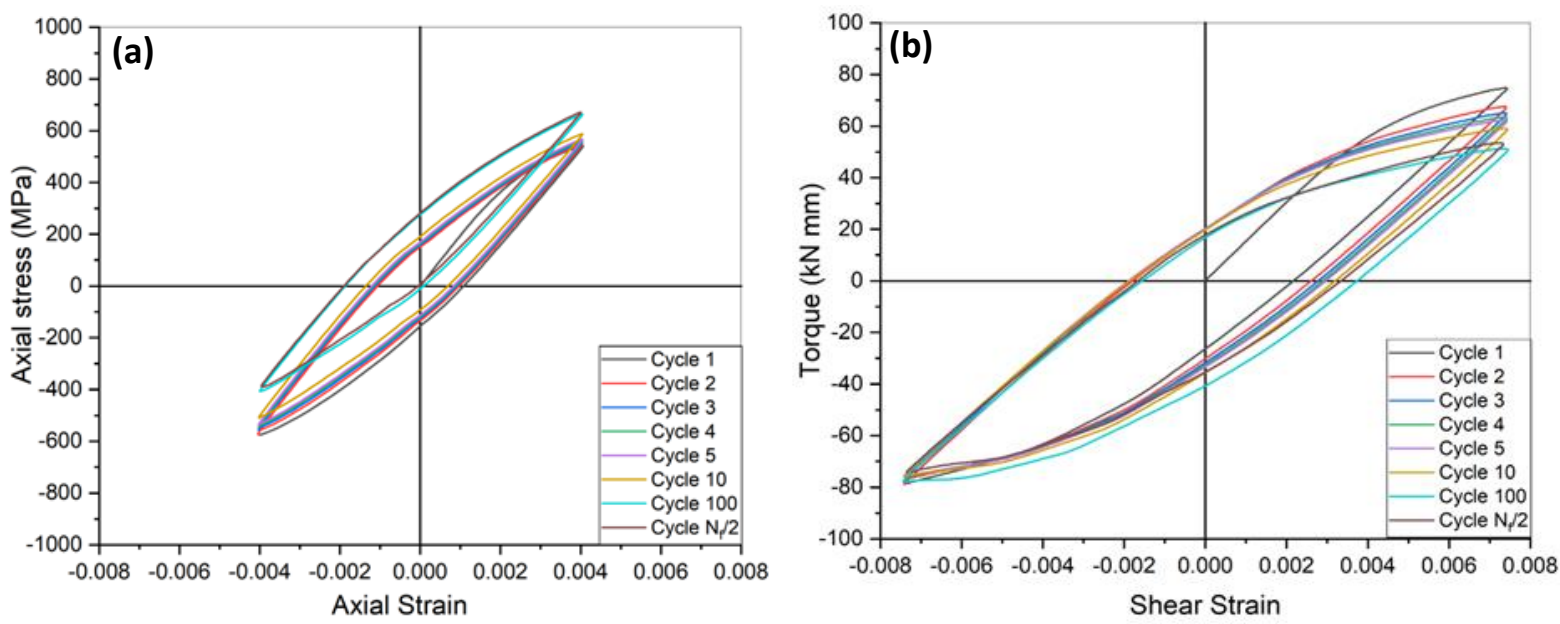

Figure 9: Hysteresis loop developed for $0.6 \%$ equivalent biaxial strains in proportional loading for pearlitic steel (a) axial stress-strain response and (b) torque-strain response.
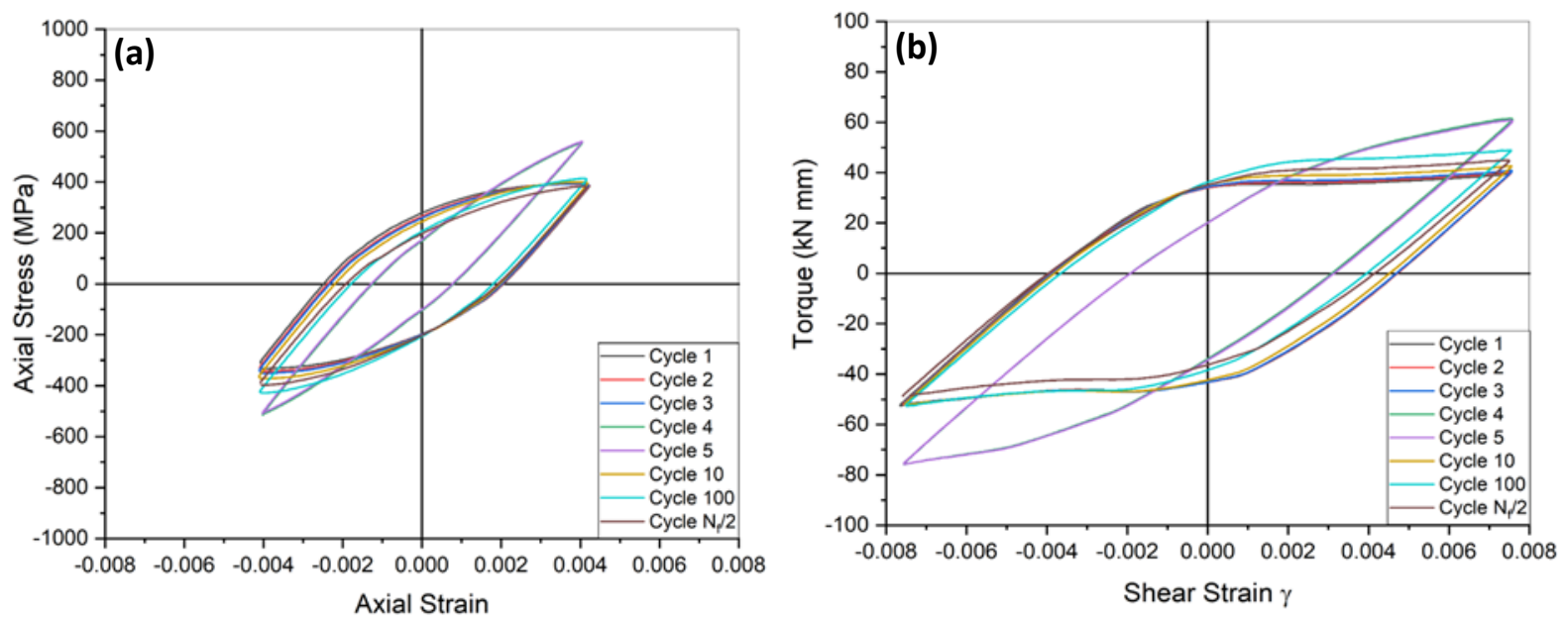

Figure 10: Hysteresis loop developed for $0.6 \%$ equivalent biaxial strains in proportional loading for manganese steel (a) axial stress-strain response and (b) torque-strain response. 

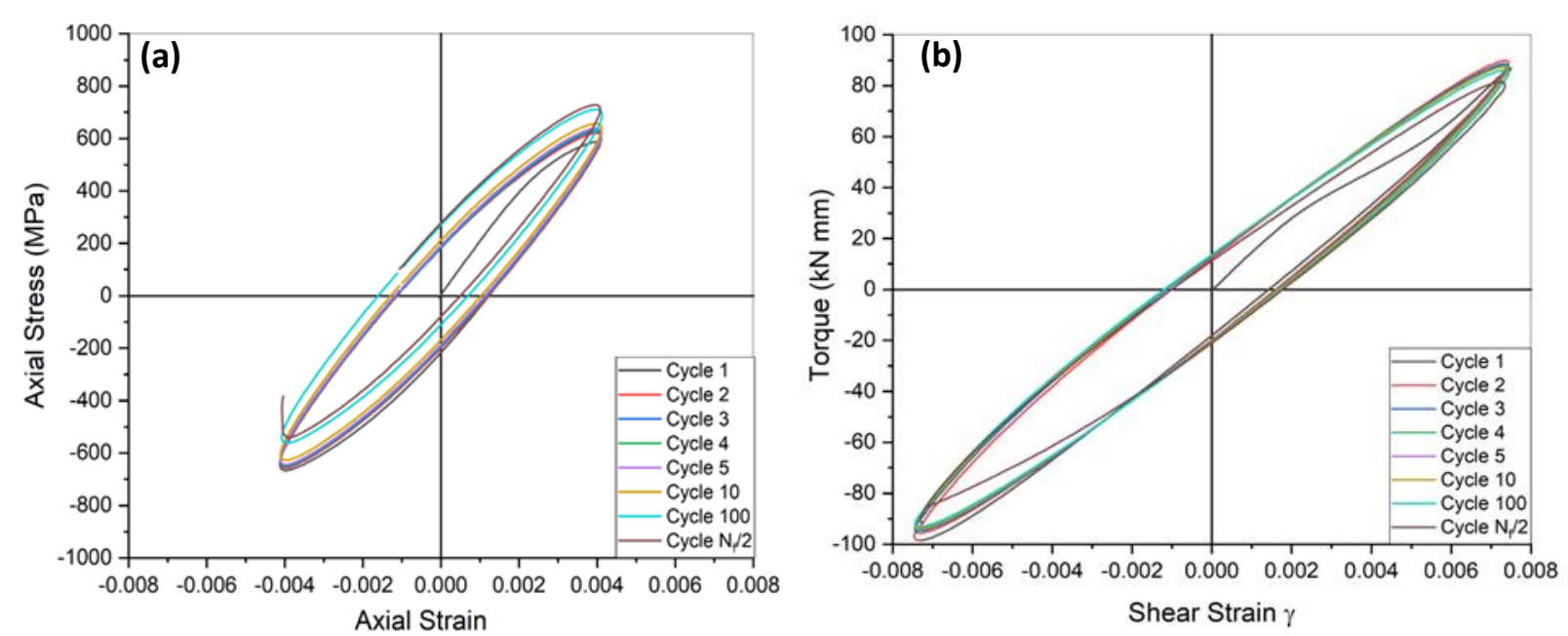

Figure 11: Hysteresis loop developed for $0.6 \%$ equivalent biaxial strains in non-proportional loading for pearlitic steel (a) axial stress-strain response and (b) torque-strain response.
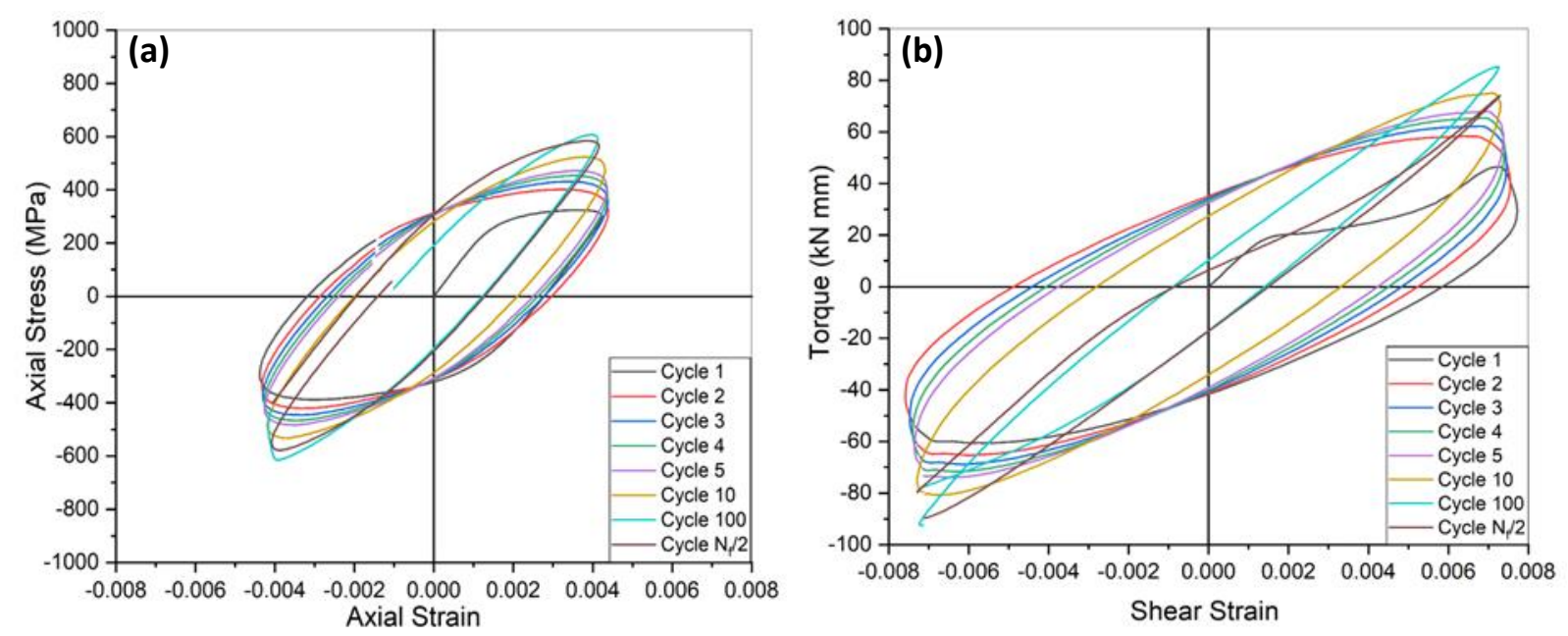

Figure 12: Hysteresis loop developed for $0.6 \%$ equivalent biaxial strains in non-proportional loading for manganese steel (a) axial stress-strain response and (b) torque-strain response.

The hysteresis loops for the compressive mean strain conditions showed ratcheting behavior. In case of manganese steel, the loops were stabilized basically after the first compressive loading. Due to the low monotonic hardening rate, no large mean stress was introduced by the mean strain imposed. Thus, the ratcheting could be easily described by monotonic plastic flow, and the continued cycling is little affected. However, the pearlite required more cycles to adjust to the mean strain and stabilize at low mean stress. Also, the stress range over which the stabilization occurred was higher in case of pearlite than manganese steel.

The area within the hysteresis loop correlates to the plastic strain energy density under low cycle fatigue loading. Fatigue damage is characterized by absorption of irreversible plastic energy which influences fatigue life. In LCF the accumulated plastic deformation is the primary reason for the fatigue. Morrow [29] suggested that the plastic strain energy per cycle is a useful criterion to measure the fatigue damage per cycle since the cyclic plastic strain is related to the movement of dislocations and the cyclic stress is associated with the resistance against their motion. Hence, the fatigue resistance of a metal can be characterized in terms of its capacity to absorb and dissipate plastic strain energy; this has been applied in numerous studies since then, also recent ones [16, 31-32]. Due to use of solid specimens for the biaxial tests, it was not possible to calculate the exact values of the plastic strain energy density of the materials (as exact stress values could not 
be obtained) except for the uniaxial loading. However, a comparative analysis of the area under the loop from the above hysteresis curves indicates that the manganese steel has higher plastic strain energy density compared to the pearlite at $N_{\mathrm{f}} / 2$. In the case of uniaxial loading, the plastic strain energies were comparable in both the materials. In the case of biaxial proportional loading both axial and shear plastic strain energy was higher for manganese steel than for pearlite. In the case of biaxial out-of-phase non-proportional loading the axial plastic strain energy was higher, but the shear plastic strain energy was lower for manganese than pearlite. A comparison between in-phase proportional and out-of-phase nonproportional loading indicates out-of-phase loading has higher plastic strain energy density for both the materials.
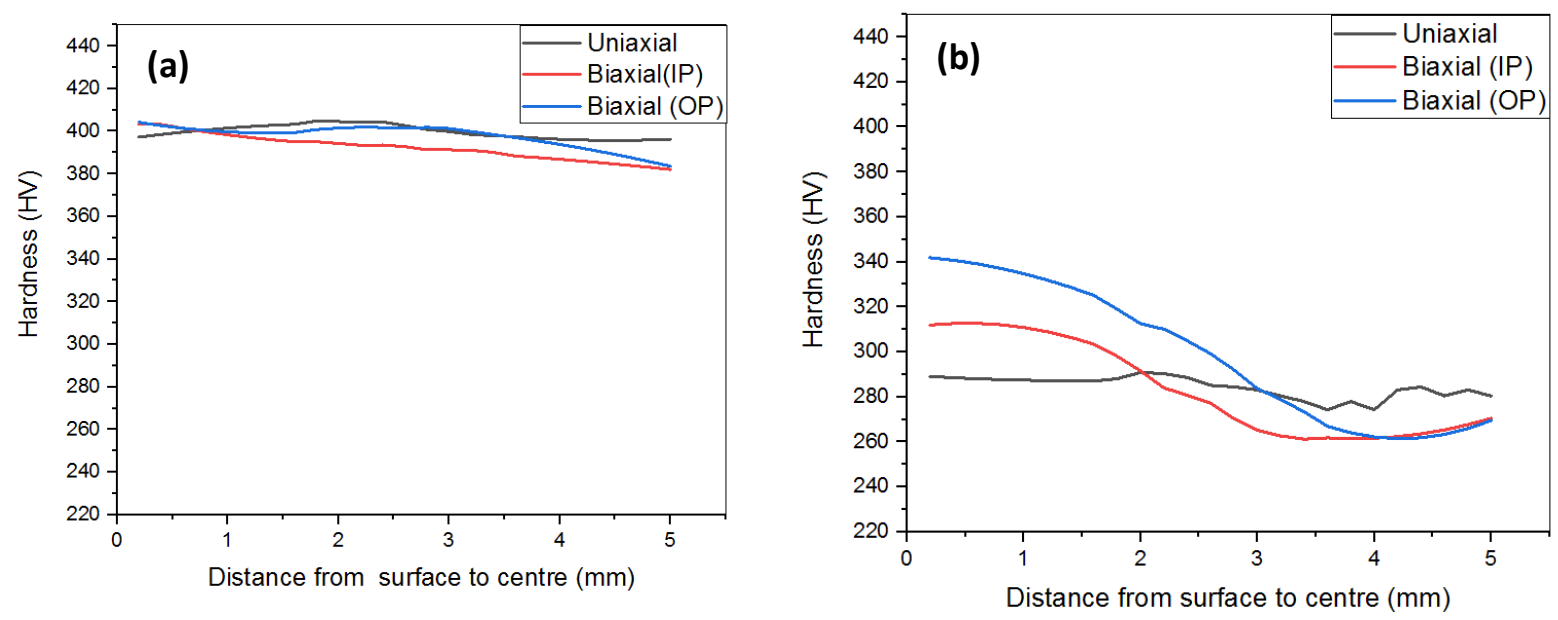

256 Figure 13: Hardness as a function for radial distance for a) pearlitic steel and b) manganese steel.

The deformation due to fatigue under different conditions was studied through hardness change. The hardness measurements across the radius of the deformed fatigue samples under the different conditions of loading are shown in Figure 13. For the pearlitic steel, there is no significant change in hardness after deformation under different conditions. It maintains a uniform average hardness of about $400 \mathrm{HV}$. The extent of hardening is significantly higher in manganese steels compared to pearlitic steel. The hardness is uniform for the uniaxial case across the radius due to uniform distribution of strain. For the biaxial cases, the maximum shear strains are at the surface and zero at the center accordingly, the bi-axial loading causes significant non-proportional hardening which is evident from the figure. The maximum hardness is obtained at the surfaces of around $340 \mathrm{HV}$ for out-of-phase non-proportional loading and $310 \mathrm{HV}$ for in-phase proportional loading which gradually falls to $260 \mathrm{HV}$ at the center.

\section{Microstructure}

The microstructures of the failed specimens were studied after the fatigue deformation. The optical micrographs (Figure 14-16) of the head hardened pearlitic steel do not show significant observable changes in the microstructure under the different conditions. The difference in the mechanical properties can, therefore, be attributed to dislocation density changes in the structure which is evident from the TEM studies (see below). The deformed microstructure of the manganese steel exhibits a structure with grains showing intense deformation bands. These bands can be deformation twins or stacking faults or dislocation boundaries. Differentiation between them is not possible from the optical micrographs. The density and morphology of the bands differ for the different conditions of loading with increasing density and decreasing spacing of the bands for biaxial non-proportional loading. The bands are in different directions and in some grains, the bands are intersecting each other. Inclusions are also evident in the micrographs. Inclusions may create local discontinuities and stress concentrations that can initiate crack formation 

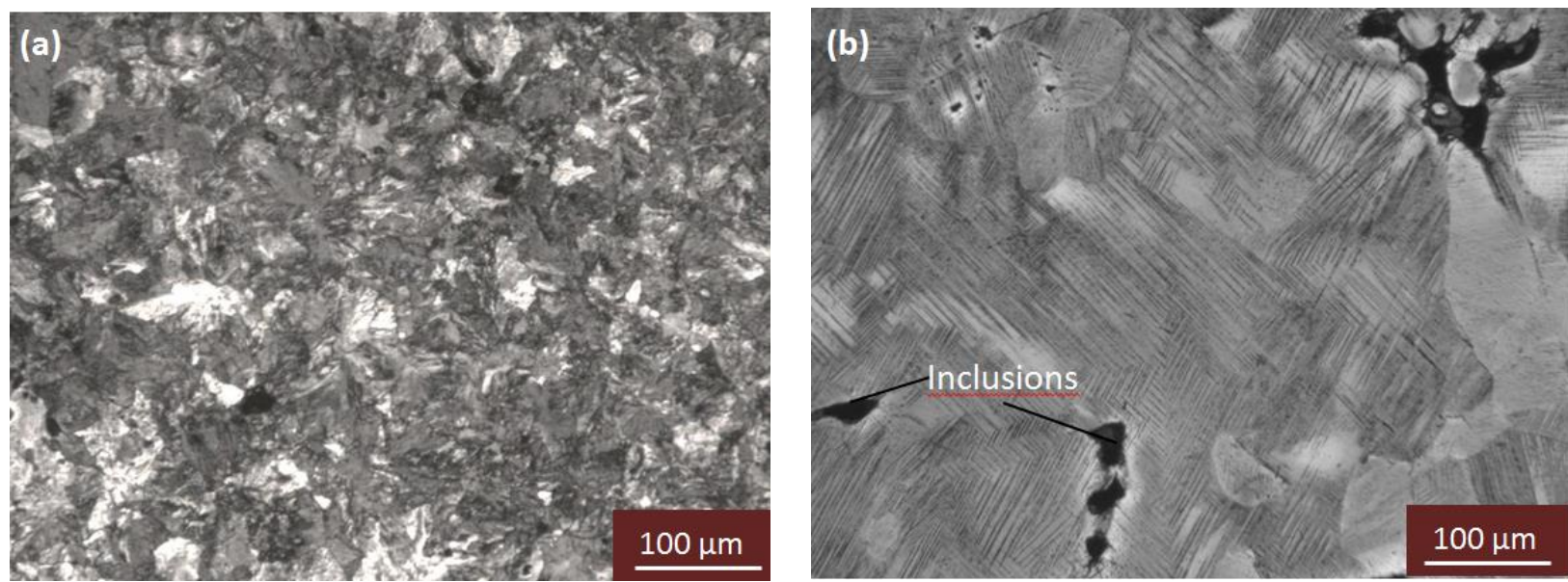

278 Figure 14: Optical micrographs of fatigue deformed specimens at $0.6 \%$ uniaxial strain amplitude (a) pearlitic steel and 279 (b) manganese steel.
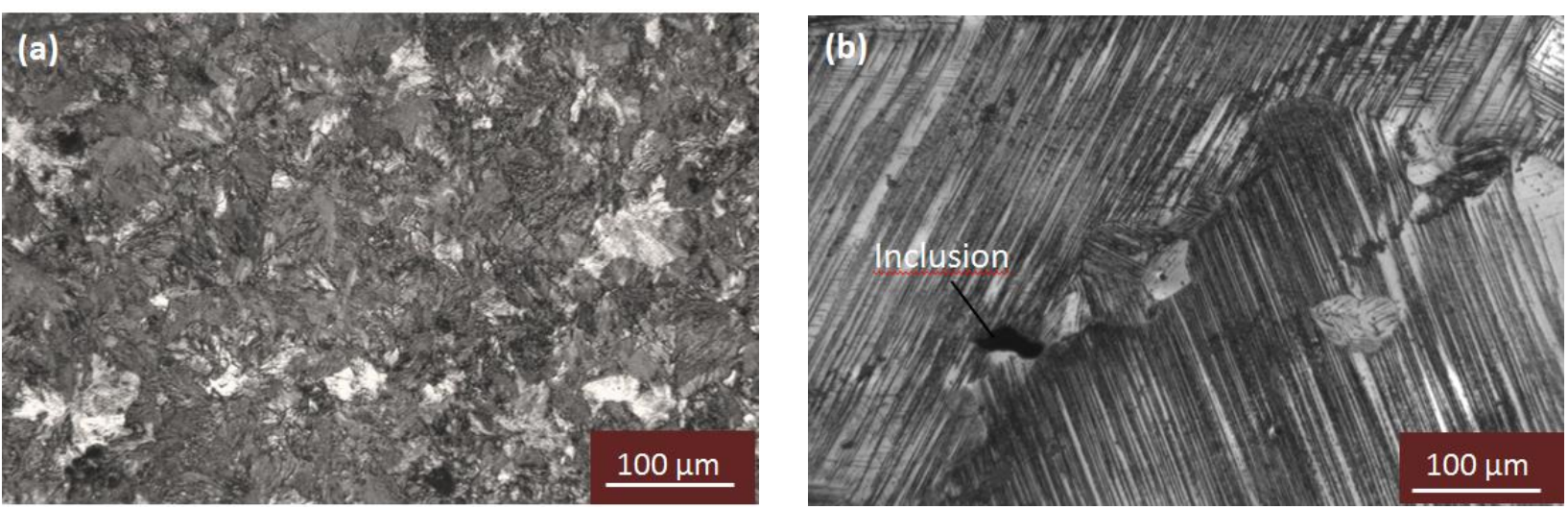

Figure 15: Optical micrographs of fatigue deformed specimens at $0.6 \%$ strain amplitude biaxial proportional loading (a) pearlitic steel and (b) manganese steel.
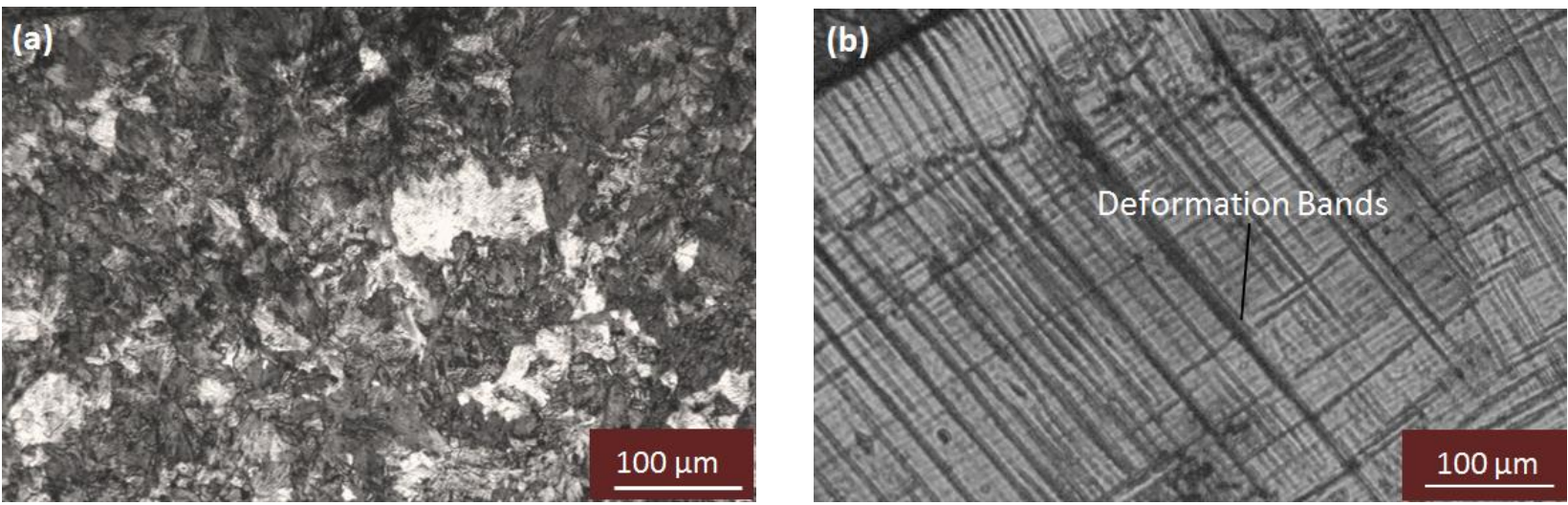

Figure 16: Optical micrographs of fatigue deformed specimens at $0.6 \%$ strain amplitude biaxial non-proportional loading (a) pearlitic steel and (b) manganese steel.

Figure 17 shows the pearlitic microstructure obtained from TEM studies with alternating ferrite and cementite lamellae in the three different fatigued samples. As $0.6 \%$ equivalent strain do not introduce observable changes in the interlamellar spacing, the present investigation focuses on the dislocation morphology and density in the ferrite lamellae. The 
dislocation tangles have been observed in all three samples, representing the typical low-strain pearlitic deformation microstructure [33-34]. These dislocations are believed to nucleate at interfaces caused by elastic incompatibility stresses between the ferrite and cementite phases [35-37], and glide in the ferrite lamellae to form dislocation tangles. Straining during constant amplitude fatigue testing causes very little hardening. However, it is interesting to note that the dislocation density is significantly different in the 3 samples; it increases from $4.9 \pm 1.4 \times 10^{14} \mathrm{~m}^{-2}$ in the uniaxial sample, to $8.5 \pm$ $2.1 \times 10^{14} \mathrm{~m}^{-2}$ in the in-phase proportional biaxial sample, to $1.0 \pm 1.4 \times 10^{15} \mathrm{~m}^{-2}$ in the out-of-phase non-proportional biaxial sample (See Table 4). In biaxial fatigue loading, slip systems in other directions are activated as compared to uniaxial loading. In biaxial out-of-phase non-proportional loading, the main reason for the higher dislocation density is suggested to be the strain path change and activation of latent slip systems [38]. Thereafter, the cyclic softening is less compared to in-phase proportional loading because it is compensated by non-proportional hardening. In the end, the strain hardening from the dislocation density increase is balanced by the strain softening from the ordering of dislocations with strain path change, and that is why the hardness of three specimens are still comparable, as observed in Figure 13.
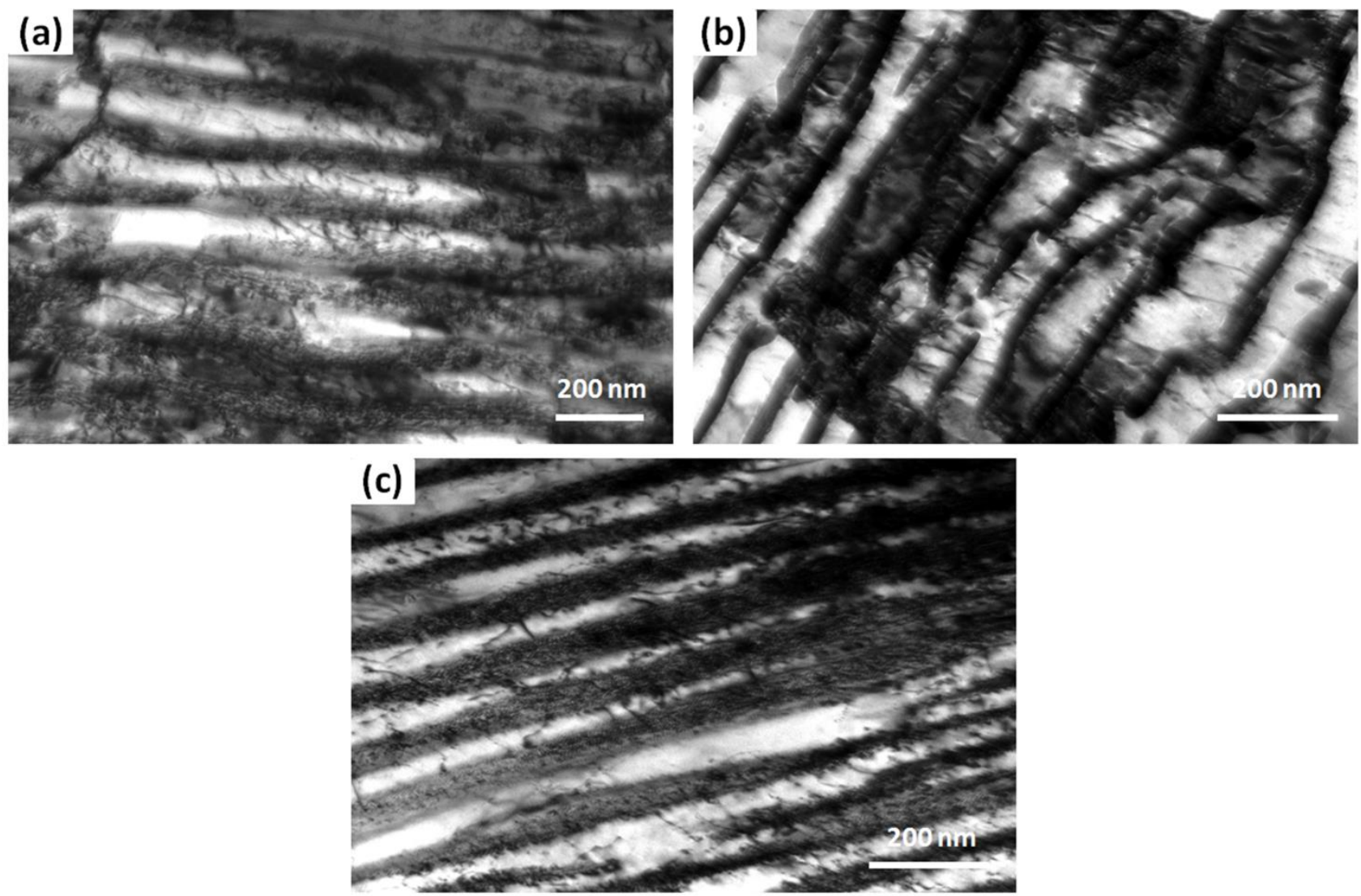

Figure 17: TEM micrographs showing the deformation microstructure in the low cycle fatigued pearlitic samples: (a) $0.6 \%$ uni-axial fatigue, (b) $0.6 \%$ in-phase proportional biaxial fatigue and (c) $0.6 \%$ out-of-phase non-proportional biaxial fatigue.

Figure 18 shows the different dislocation and stacking fault structures in the three samples of austenitic manganese steel deformed to the equivalent strain of $0.6 \%$. The microstructures are composed of dislocation cells with dislocation tangles inside, intersected with straight stacking fault lamellae. In the uniaxial fatigue sample, the dislocation cell size is $\sim 500$ $\mathrm{nm}$, the dislocation density inside the cells is $3.4 \pm 0.57 \times 10^{14} \mathrm{~m}^{-2}$ and the spacing between stacking fault lamellae is $~$ $1.2 \mu \mathrm{m}$ (see Table 4). Intersecting stacking fault lamellae with dislocation tangles between them are observed in the inphase proportional biaxial fatigued sample where the average spacing between neighboring stacking fault lamellae is 330 $\mathrm{nm}$ and the dislocation density in the cells formed by intersecting stacking fault lamellae is $1.1 \pm 0.13 \times 10^{14} \mathrm{~m}^{-2}$. Dense 
parallel stacking fault lamellae with dislocations and dislocation tangles between them are seen in the out-of-phase nonproportional biaxial fatigued sample where the average spacing between neighboring stacking fault lamellae is $\sim 60 \mathrm{~nm}$ and the dislocation density between the parallel stacking fault lamellae is $\sim 5 \pm 0.13 \times 10^{14} \mathrm{~m}^{-2}$. Detailed values are given in Table 4.

For the manganese steel, the microstructure is thus quite different for the three deformation modes at the same equivalent strain. In the uniaxial fatigue mode, multiple dislocation slip together with the increased friction stress against dislocation glide due to the high concentration of solute atoms are responsible for the formation of the observed dislocation cell structure. However, when the shear mode is introduced in the in-phase and out-of-phase biaxial fatigue test, formation and growth of stacking faults play an important role together with dislocation nucleation, gliding and dislocation tangle formation. For the formation and growth of a stacking fault, any perfect dislocation with a Burgers vector can be dissociated into two partials, for example, two Shockley partials. The local applied stress generally exerts two different forces on the partials which determine the displacement of each dislocation and consequently the nature of the stacking fault ribbons. Moreover, the low stacking fault energy of the manganese steel allows the width of the ribbons to increase enough to reach values giving an extended fault bounded by independent partial dislocations, where the density of independent partial dislocations, and therefore the density of extended stacking faults, increases with the strain [39]. For the present small strain, abundant stacking faults are observed for both in-phase proportional and out-of-phase nonproportional biaxial fatigued samples, as previously reported in single-crystal manganese steel deformed to < $1 \%$ in tension [10]. However, the in-phase proportional biaxial fatigue results in parallel stacking faults in different directions while the out-of-phase non-proportional biaxial loading introduce a high density of parallel stacking faults with much smaller stacking fault spacing. The dislocations are obstructed at the stacking faults or are pinned down by obstacles causing pile-up which cause hardening and finally formation of dislocation tangles.

The dislocation density for in-phase proportional biaxial loading is lower compared to uniaxial loading but there are interactions of stacking faults with dislocations as well as a decrease in stacking fault lamellae width. Hence, the hardening cannot be explained with dislocation entanglement. The presence of intersecting stacking faults and their interaction with dislocations however contribute to the additional hardening behavior. For non-proportional biaxial low cycle fatigue, the effect of strain path change is predominant with cyclic hardening. Higher non-proportional hardening clearly shows that the latent slip systems are active in this case [38]. The dislocation density is high and the width of the stacking fault the latent slip systems are active in this case [38]. The dislocation density is high and the
lamellae decreases for non-proportional biaxial low cycle fatigue loading in manganese steel. 

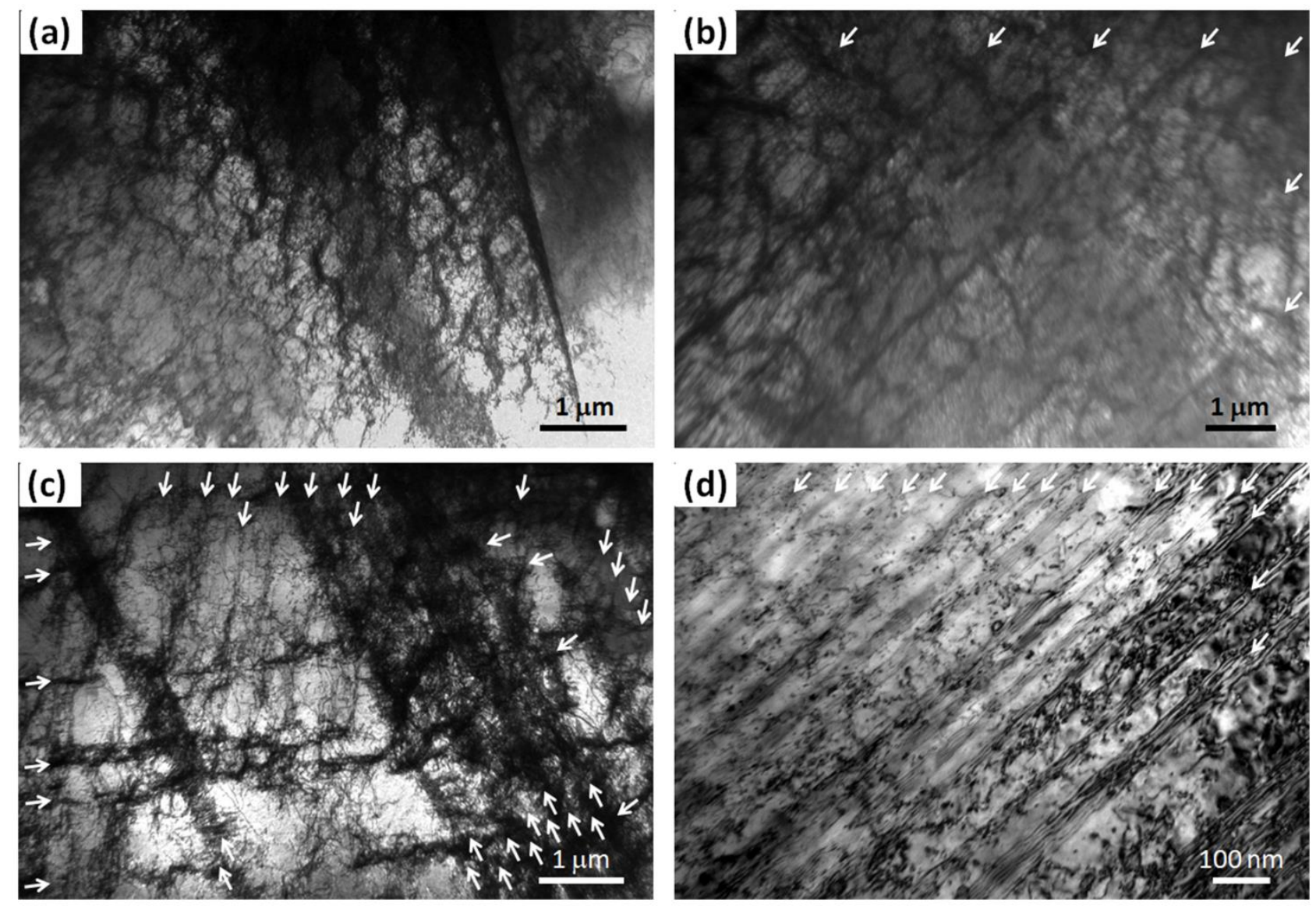

343

344

345

346

347

348

Figure 18: TEM micrographs showing the dislocation structures and stacking faults in the LCF samples (a) dislocation cells with dislocation tangles inside and (b) straight stacking fault lamellae across dislocation cells in $0.6 \%$ uniaxial fatigue sample, (c) intersecting stacking fault lamellae with dislocation tangles between them in $0.6 \%$ in-phase proportional biaxial fatigue sample and (d) dense parallel stacking fault lamellae with dislocation tangles between them in $0.6 \%$ out-of-phase non-proportional biaxial fatigue sample. The electron beam axis is close to the [213] direction of fcc austenite. The white arrows point out the stacking fault lamellae.

Table 4: The dislocation density of pearlite and manganese steel and stacking fault lamellae width for the manganese steel:

\begin{tabular}{|l|c|c|c|}
\hline \multirow{2}{*}{ Condition } & \multicolumn{2}{|c|}{ Dislocation Density $\left(\mathrm{m}^{-2}\right)$} & Stacking Fault lamellae \\
\cline { 2 - 4 } & Pearlitic Steel & Manganese Steel & Manganese Steel \\
\hline Uniaxial & $4.9 \pm 1.4 \times 10^{14}$ & $3.4 \pm 0.57 \times 10^{14}$ & $\sim 1.2 \mu \mathrm{m}$ \\
\hline Biaxial (Proportional) & $8.5 \pm 2.1 \times 10^{14}$ & $1.1 \pm 0.13 \times 10^{14}$ & $330 \mathrm{~nm}$ \\
\hline Biaxial (Non-proportional) & $1.0 \pm 1.4 \times 10^{15}$ & $5.0 \pm 0.13 \times 10^{14}$ & $\sim 60 \mathrm{~nm}$ \\
\hline
\end{tabular}

\section{Analysis on suitability as crossing material}

Pearlite steel is a good candidate for fatigue loading where the plastic deformation is limited. It has high yield strength but limited work hardening capability over small plastic strain. Manganese steel gains its strength through work hardening retaining it capability to absorb plastic energy and hence have a better toughness. Therefore, it serves as a good candidate 
for impact loading which occurs at the crossing. Also manganese steel has less ductility exhaustion (plastic deformation induced damage rate) in fatigue compared to pearlite steel. It is thus a good choice in rail road crossings where the fatigue loading includes plastic strain. The mode of deformation in pearlitic steels is limited only to slip whereas twinning, slip, and formation of stacking fault occur in manganese steel. These contribute to the additional hardening. In this study, the effects of mean strain and non-proportional loading were studied separately. The mean strain, which essentially leads to a monotonic pre-deformation of the manganese steel (cf Figure 8b), caused a hardening effect of some $75 \mathrm{MPa}$ that survived the following cyclic deformation (seen in Figure 4). The non-proportional loading gave a hardening that made manganese steel reach close to the cyclic strength of the pearlitic material deformed in an identical manner (some $25 \mathrm{MPa}$ difference, see Figure 6). Thus, if those contributions are additive, the stress amplitude response would actually be higher for the manganese steel than for the pearlitic steel. This could be the reason why manganese steels do well in the application where monotonic pre-straining as well as non-proportional straining is generated by the rolling contact fatigue loading.

This laboratory study encompassed only constant strain amplitudes and pure biaxial loading and can thus not fully explain why manganese steels perform well in railway crossings. But since the loading in the crossings is even more complex considering the contact stress variations in both location and magnitude, the manganese steel is likely to develop more entangled dislocation structures which increase the deformation resistance and cyclic strength further. Since the loading in field is force controlled rather than displacement controlled, the plastic strain amplitude decreases for given loads. The material in the crossings thereby accumulates less plastic strain energy which typically leads to decreased fatigue damage. The reason for the shorter fatigue life of the manganese steel specimens in this study could be the presence of rather high tensile stresses in the laboratory test; the microstructure with inclusions, very large grains and weak/brittle grain boundaries is prone to cracking under tensile stress. In the rail (or maybe we should say crossing), compressive and shear stresses dominate to a much larger degree, and the microstructural features (flaws) are not that detrimental.

\section{Conclusions:}

The low cycle fatigue behavior of two different steels extracted from railway crossings have been studied under uniaxial and biaxial loading conditions. The deformed microstructure after fatigue has been investigated using TEM and relations between microstructural changes and mechanical properties were analyzed.

The softer manganese steel exhibited cyclic hardening behavior under all conditions, as fatigue straining caused dislocation and stacking fault generation and interaction between them. The highest hardening was obtained for biaxial non-proportional loading due to strain path change and thus activation of multiple slip systems.

The harder pearlitic steel showed softening behavior as straining caused reorganizing of the dislocations into tangles and a cell structure. However, biaxial non-proportional loading showed some hardening in the initial cycles due to multiple slip systems being activated and also increased dislocation density.

Whereas pearlite steel was insensitive to the mean strain, manganese steel showed mean strain hardening with a decrease in fatigue life under constant strain amplitude loading. The dislocation morphology was found to be similar for pearlite under all conditions; the difference in mechanical behavior is due to a change in dislocation density with the biaxial nonproportional loading having the highest dislocation density. For manganese steel, the in-phase proportional loading results in parallel stacking faults in different directions while the out-of-phase non-proportional loading introduces a high density of parallel stacking faults with much smaller spacing and high dislocation density.

The pearlite steel had better fatigue life under all conditions tested in this laboratory study. However, the strain hardening capacity of manganese steels almost reached the cyclic strength of the pearlitic steel under identical biaxial nonproportional conditions. Since load conditions in crossings are more complex, the manganese steel is likely to reach a higher stress amplitude response than the pearlitic steel. This could be what makes manganese steel a suitable choice for crossings. 
400

401

402

403

404

405

406

407

408

409

410

411

412

413

414

415

416

417

418

419

420

421

422

423

424

425

\section{Acknowledgment:}

The authors gratefully acknowledge support from the Innovation Fund Denmark through the project "INTELLISWITCH

- Intelligent Quality Assessment of Railway Switches and Crossings" (Grant no 4109-00003B). Dorte Juul Jensen and Xiaodan Zhang further wish to acknowledge support from the European Research Council (ERC) under the European Union's Horizon 2020 research and innovation programme (grant agreement No 788567-M4D). Johan Ahlström acknowledges partial funding from the European Horizon 2020 Joint Technology Initiative Shift2Rail through contract No. 730841, from 2019 by In2Track2 under grant agreement No 826255.

\section{Data Availability:}

The raw/processed data required to reproduce these findings cannot be shared at this time due to technical or time limitations.

\section{References:}

[1] A. V. Olver: Proceedings of the Institution of Mechanical Engineers, Part J: J. of Tribol., 2005, vol. 219, pp. 313-30.

[2] D. L. McDowell: Int. J. Plast., 1995, vol. 11(4), pp. 397-421.

[3] R. I. Stephens, A. Fatemi, R. R. Stephens and H. O. Fuchs: Metal fatigue in engineering, John Wiley and Sons, New Jersey, NJ, 2001.

[4] E. G. Astafurova, M. S. Tukeeva, G. G. Zakharova, E. V. Melnikov and H. J. Maier: Mater. Charact., 2011, vol. 62, pp. 588-92.

[5] C. Efstathiou and H. Sehitoglu: Acta Mater., 2010, vol. 58, pp. 1479-88.

[6] I. Karaman, H. Sehitoglu, Y. I. Chumlyakov and H. J. Maier: Act. Mater., 2000, vol. 48(6), pp. 1345-59.

[7] W. S. Owen and M. Grujicic: Act. Mater., 1999, vol. 47, pp. 111-26.

[8] P. H. Adler, G. B. Olson and W. S. Owen: Metall. Trans. A, 1986, vol. 17, pp. 1725-37.

[9] J. Kang, F. C. Zhang, X. Y. Long and B. Lv: Mater. Sci. Eng. A, 2014, vol. 591, pp. 59-68.

[10] D. Rittel and I. Roman: Int. J. Fatigue, 1989, vol. 11(3), pp. 177-82.

[11] M. Schilke, J. Ahlström and B. Karlsson: Procedia Eng., 2010, vol. 2, pp. 623-28.

[12] C. Chen, B. Lv, F. Wang and F. Zhang: Mater. Sci. Eng. A, 2017, vol. 695, pp. 144-53.

[13] Y. Jiang and . Sehitoglu: Wear, 1999, vol. 224, pp 38-49.

[14] W. A. Glaeser and S. J. Shaffer: Book chapter "Contact Fatigue”, in ASM Handbook, 1996, vol. 19: Fatigue and Fracture, pp 331-336. 
[15] J. Ahlstrom and B. Karlsson: Wear, 2005, vol. 258, pp. 1187-93.

429 [16] P. P. Sarkar, P. S. De, S. K. Dhua and P. C. Chakraborti: Mater. Sci. Eng. A,2017, vol. 707, pp. 125-35.

430 [17] G. Kang, Q. Gao and X. Yang: Int. J. Mech. Sci., 2002, vol. 44, pp. 1647-63.

431 [18] A. Athukorala, D. V. De Pellegrin and K. I. Kourousis: Wear, 2016, vol. 366-367, pp. 416-24.

432 [19] H. Sunwoo, M. E. Fine, M. Meshil and D.H. Stone: Metall. Trans. A, 1982, vol. 13A, pp. 2035-47.

433 [20] C. L. Pun, Q. Kan, P. J. Mutton, G. Kang and W. Yan: Int. J. Fatigue, 2014, vol. 66, pp. 138-54.

434 [21] G. Kang and Q. Gao: Mech. Mater., 2002, vol. 34, pp. 809-20.

435 [22] G. Kang, Q. Gao, L. Cai, Y. Sun and X. Yang, Mater. Sci. Technol. ,202, vol. 18(1), pp. 13-16.

436 [23] S. Dhar, H. K. Danielsen, S. Fæster, C. Rasmussen, Y. Zhang and D. Juul Jensen, Wear, 2019, vol. 438-439, pp. 437203049.

438 [24] ASTM E606 / E606M-19e1, Standard Test Method for Strain-Controlled Fatigue Testing, ASTM International, West 439 Conshohocken, PA, 2019, www.astm.org

440 [25] X. Zhang, A. Godfrey, X. Huang, N. Hansen, W. Liu and Q. Liu: Proceedings of the 30th Risø international 441 symposium on materials science: nanostructured metals - fundamentals to applications, 2009, pp. 409-16.

442 [26] X. Zhang, N. Hansen, A. Godfrey and X. Huang: Acta Mater., 2013, vol. 114, pp. 176-83.

443 [27] Y. Jiang and H. Sehitoglu: Wear, 1999, vol. 224(1), pp. 38-49.

444 [28] N. Shamsei, A. Fatemi and F. D. Socie: Int. J. Plast., 2010, vol. 26(12), pp. 1680-1701.

445 [29] J. Morrow, Cyclic plastic strain energy and fatigue of metals, Internal Friction, Damping and Cyclic Plasticity, 446 ASTM International STP378-EB,1965, pp. 45-87.

447 [30] H. Christ: Book chapter "Cyclic stress-strain Response and Microstructure", in ASM Handbook, 1996, vol. 19: 448 Fatigue and Fracture, pp 73-95. DOI: https://doi.org/10.31399/asm.hb.v19.a0002354

449 [31] R. Branco, P.A. Prates, J. D. Costa, L.P. Borrego, F. Berto, A. Kotousov and F.V. Antunes; Int. J. Fatigue, 2019, $450 \quad$ vol. 124 , pp. 89-98.

451 [32] R. Branco, J. D. Costa, F. Berto, and F.V. Antunes; Theor. Appl. Fract. Mec., 2018, vol. 97, pp 340-348.

452 [33] X. Zhang, A. Godfrey, X. Huang, N. Hansen and Q. Liu: Acta Mater., 2011, vol. 59, pp. 3422-30.

453 [34] X. Zhang, A. Godfrey, N. Hansen and X. Huang: Acta Mater., 2016, vol. 61, pp. 4898-4909.

454 [35] M. Dollar, I. M. Bernstein and A. W. Thompson, Acta Metall., 1988, vol. 36, pp. 311-20.

455 [36] S. A. Hackney and G. J. Shiflet: Scr. Mater., 1986, vol. 20, pp. 389-394. 
456 [37] X. Zhang, N. Hansen, A. Godfrey and X. Huang: Mater. Sci. Technol., 2018, vol. 34, pp. 794-808.

457 [38] F. Barlat, J. M. Ferreira Duarte, J. J. Gracio, A. B. Lopes and E. F. Rauch: Int. J. Plast., 2003, vol. 19(8), pp. 121545844.

459 [39] J. F. M. Vergnol and J. R. Grilhe : Journal de Physique, 1984, vol. 45 pp. 1479-90. 